\title{
ECOSOFÍA-ANTROPOÉTICA: UNA RE-CIVILIZACIÓN DE LA HUMANIDAD
}

\author{
Milagros Elena Rodríguez \\ Mireya Mirabal Rodríguez* \\ https://orcid.org/0000-0003-4843-9058
}

RECIBIDO: Agosto 2019 / ACEPTADO: Febrero 2020 / PUBLICADO: Mayo 2020

Como citar: Rodriguez, Milagros: Mirabal Rodríguez, Mireya (2020). Ecosofía-antropoética: una recivilización de la humanidad. Telos: revista de Estudios Interdisciplinarios en Ciencias Sociales, 22 (2), Venezuela. (Pp.295-309).

DOI: www.doi.org/10.36390/telos222.04

\section{RESUMEN}

¡Sálvese quien pueda! Es el pensar del que sin tener a Dios en su sentir, con Él y en el mundo se siente desprotegido del sistema y arrancado de la vida en el planeta. Esta investigación insiste en que antes que la tierra muera vale la pena volver a civilizar a la humanidad, re-civilizar, por ello una exhortación a la humanidad entera pidiéndole contrición y enmienda es urgente, que cada quien pueda cumplir con su papel de responsabilidad ante el mundo ¿dónde quedo la ética del cuidado de la tierra, la de sí mismo, la de nuestros congéneres, la regulación de nuestro accionar? Es una crisis que desde la transmetodología transcompleja, en un proyecto transmodernista y el transmétodo: hermenéutica comprensiva, ecosófico y diatópica se analiza la diada ecosofía-antropoética como una re-civilización de la humanidad, como objetivo de la investigación; con autores consultados como: Morín (2006), Panikkar (2007), Deleuze y Guattari (1980); entre otros. Es urgente al retomar el cambio de pensamiento, reformarlo, reconstruirlo, volver a significar el planeta en la vida del ser humano, re-civilizar el pensamiento, estamos en el deber antropoético de emprender una camino que nos dignifique ante el mundo y Dios Creador y Señor.

Palabras clave: Re-civilización, ecosofía, antropoética, Dios, humanidad.

\section{Ecosophy-anthropology: a re-civilization of humanity}

\begin{abstract}
Every man for himself! It is the thinking of the one who, without having God in his feeling, with Him and in the world feels unprotected from the system and torn from life on the planet. This
\end{abstract}

\footnotetext{
" PhD. en Ciencias de la Educación, Doctora en Patrimonio Cultural, Doctora en Innovaciones Educativas, Magíster Scientiarum en Matemáticas, Licenciada en Matemáticas, Docente Investigadora Titular, Universidad de Oriente, Departamento de Matemáticas, República Bolivariana de Venezuela, con más de 100 publicaciones entre libros, capítulos y artículos. Tutora de Pregrado y Postgrado. Correo electrónico: melenamate@hotmail.com http://melenamate.blogspot.com/

"Investigadora Doctorando en Ciencias de la Educación, Universidad Latinoamericana y el Caribe, Especialista en Planificación y Gerencia Educativa, Licenciada en Trabajo Social, Universidad Bolivariana de Venezuela, República Bolivariana de Venezuela, mirmirabal@gmail.com
} 
research insists that before the earth dies it is worth re-civilizing humanity, re-civilizing, so an exhortation to all humanity asking for contrition and amendment is urgent, that everyone can fulfill their role of responsibility before the world where is the ethics of the care of the land, that of itself, that of our fellow man, the regulation of our actions? It is a crisis that, from trans-complex transmethodology, in a transmodernist project and the transmethod: comprehensive, ecosophical and diatopic hermeneutics, the ecosystem-anthropoetic dyad is analyzed as a re-civilization of humanity, as the objective of research; with authors consulted as: Morin (2006), Panikkar (2007), Deleuze and Guattari (1980); among others. It is urgent to resume the change of thought, to reform it, to rebuild it, to re-signify the planet in the life of the human being, to re-civilize the thought, we are in the anthropotic duty to undertake a path that dignifies us before the world and God the Creator and Lord.

Keywords: Re-civilization, ecosophy, anthropoetics, god, humanity.

\section{Rizoma: introito, crisis de la inhumana humanidad y categorías investigativas}

Sin duda vivimos en una humanidad de sentimientos empobrecidos, domesticada y desprovista de una práctica cultural, en un egoísmo y carente de la condición humana, claro que sus excepciones están presentes pues el hombre es el único demens capaz de matar por antojo o de amar desenfrenadamente. ¿De qué le ha servido al ser humano grandes avances que nos alejan más de ser felices, de la paz y el convivir en plena contaminación, escasez, acaparamiento, mientras por otro lado, los cinturones de miseria son insoportables, la guerra busca la victoria muy lejos de la paz, el egoísmo por nuestros congéneres gana al amor? El decaimiento de los dogmas científicos va cada vez al infortunio del ser humano.

Lorenz (1984), pregunta: "¿para qué le sirve a la Humanidad su multiplicación desmedida, su espíritu y competencia que se acrecienta sin límite hasta rayar en lo demencial, (...) horripilante, la progresiva enervación del hombre apresado por un urbanismo absorbente, y así sucesivamente?" (p.6). Dicho autor responde dilucidando que los ocho pecados de la humanidad son: la superpoblación, asolamiento del espacio vital, la competencia consigo mismo, muerte en vida del sentimiento, decadencia genética, quebrantamiento de la tradición, formación indoctrinada y las armas nucleares.

La carencia de sabiduría para habitar en el planeta es notoria, ¿de dónde viene la sabiduría?, ¿cómo llegar al máximo desarrollo de la Inteligencia Espiritual? Dios como máxima expresión de religación y amor nos provee de la sabiduría, nos regula y nos da normas del bien vivir. De acá, la ecosofía como categoría constitutiva de la indagación. La ecosofía, que es la conjunción de las tres ecologías, la social, espiritual y ecológica; en los estudios que más adelante se citan a los largo del texto, uniendo la filosofía, el arte, la ciencia y toda producción humana a la tierra, deviene, a una nueva inteligencia del oikos, la casa del mundo y a una renovación práctica del ethos, los modos de habitar.

Desde luego, el ser humano en solitario no planifica guerras, son sistemas a los cuales el hombre le es obediente. Encinas (2009), afirma que desde la era paleolítica hasta la actualidad, se ha ido olvidando la realidad e indagación de la misión del hombre, de este ser que lo distingue como ser pensante y accionado, del animal, afirma que esto convenía a egoístas intereses, deliberadamente, para la hegemonía; no es extraño las consecuencias de su poderío. Ha resultado de cultura de la muerte perversa, cargada de dolor, sufrimiento y más muerte. Con 
ello, la pérdida de consciencia, el execrar la ética de las ciencias, de la educación y de la forma de hacer politiquerías de bajo extracto humano. ¡Sálvese quien pueda! Es el pensar del que, sin tener a Dios en su sentir, con Él y en el mundo se siente desprotegido del sistema y arrancado de la vida en el planeta.

Esta investigación insiste en que antes que la tierra muera vale la pena volver a civilizar a la humanidad, re-civilizar, por ello es urgente una exhortación a la humanidad entera pidiéndole contrición y enmienda, que cada quien pueda cumplir con su papel de responsabilidad ante el mundo ¿dónde quedó la ética del cuidado de la tierra, la de sí mismo, la de nuestros congéneres, la regulación de nuestro accionar? De allí, que la categoría antropoética tiene sentido como constitutiva, conjuntamente con ello la antropolítica. Morín (1999), la antropoética supone "la decisión consciente y clara: de asumir la humana condición individuo-sociedad-especie en la complejidad de nuestra era, de lograr la humanidad (...) asumir el destino humano en sus antinomias y su plenitud" (p.101).

En tanto la antropolítica, se entiende de acuerdo con Osorio (2011), "como estrategia emergente para enfrentar el desafío humano en la era planetaria" (p.51). Todas estas posibilidades ecosóficas, antropolíticas y antropoéticas no tienen cabida en el paradigma moderno, ni bajo el reduccionismo donde el ser humano se reduce a producir y hacer y su condición humana es desconocida o renegada a segundo plano, no conviene para el eje opresor y globalizado las subjetividades del ser humano.

Por ello, más allá de los paradigmas, en un transparadigma, trans que significa más allá, la transcomplejidad, implica el entendimiento de los múltiples niveles de realidad; designa la conjunción de lo simple y disciplinar, lo que atraviesa y trasciende a éstas; además, la lectura de lo transcomplejo implica el acercamiento entre ciencia, arte y poesía, lo cual en definitiva, es una episteme que propicia el encuentro, el dialogo y la reconciliación entre las distintas lógicas y racionalidades. La complejidad aporta elementos sustantivos a la re-civilización y posibilidad de realización del ser humano en la diada: ecosófica-antropoética.

Morín (2006), señala que el estudio de cualquier aspecto de la experiencia humana debe ser multifacético, por ello la complejidad comprende todo aquello que clarifica, ordena y precisa el conocimiento de esa experiencia, integrando las disciplinas del saber para generar conocimiento multidimensional, no parcelado, ni reduccionista o simplificador, reconociendo lo inacabado e incompleto de todo conocimiento. Es la complejidad entonces, una metáfora para pensar, con Edgar Morín en todas sus obras, la Humana Conditio en la era planetaria.

Con todo este pensar complejo de acuerdo con Morín y Kern (1993), "habría necesidad de una ciudadanía planetaria, de una conciencia cívica planetaria, de una la opinión intelectual y científica planetaria, de una opinión política planetaria" (p.117). Es de hacer notar que son los preámbulos para una política planetaria, la antropolítica, que al mismo tiempo es una circunstancia para la formación de estos acuerdos y la toma de conciencia.

Morín (2006), en su método: la humanidad de la humanidad, ratifica el develar la identidad humana desde la teoría de la complejidad; pese al avance de las ciencias estas son esencias para revelar y conocer, re-civilizar es entonces también avanzar en la educabilidad y la transformación del pensamiento, "pues dime como piensas y te diré cómo accionas". Se trata de deconstruir los conocimientos parcelados y englobarlos con lo espiritual, lo social, los puentes ecosóficos unitivos que nos conlleve a una humanidad revitalizada y realmente consciente de quienes somos, y cuál es nuestra responsabilidad en el planeta. 
El estudio de la espiritualidad es de vital importancia; regresar el estudio de la Biblia a las instituciones educativas, el desarrollo de la Inteligencia Espiritual. Son tareas por resolver en la re-civilización que parecen trilladas porque la problemática es muy estudiada; pero si el estudio parte de las mismas parcelas, del mismo reduccionismo; si el paradigma modernista 0 postmodernista sigue anclado en las mentes de los seres humanos los resultados serán los mismos: las acciones inhumanas del inhumano ser, no en vano Morín (2008), afirma que la humanidad actual es como el Titanic. ¿Hacia dónde apunta esta metáfora?

La necesidad de re-civilizar es urgente en el conocimiento, re-civilizar el conocimiento reduccionista equivocado, parcelado responsable del accionar inhumano, según Morín (2011), "la humanidad está imbuida en una dialéctica del conocimiento porque existe una clara distancia entre el acontecimiento y la consciencia de su significado" (p. 19).

Pero también re-civilizar el pensamiento y el aspecto cognitivo del pensar, pues hay de acuerdo con Morín (2011), "dos tipos de carencias cognitivas: La ceguera propia que exige un conocimiento interdisciplinar; el occidentalocentrismo, nos da la ilusión de poseer lo universal" (p. 19). La re-civilización no hay duda que alcanza todas las aristas y complejidades del inhumano y humano ser humano, así con Morín (2011), "la intoxicación consumista de la clase media se desarrolla mientras se degrada la situación de las clases más pobres y se agravan las desigualdades" (p. 23). Por ello, hay que re-civilizar la riqueza en manos de unos pocos y alcanzar condiciones mínimas deseables de habitar en el planeta.

Sin duda, un aspecto que se debe re-civilizar son los antivalores, el ser humano, afirma Morín (2011) "ha aportado los lados más sombríos del individualismo: el egocentrismo, la autojustificación y el afán de lucro" (p.27). Desde luego, las autoras no quieren agobiar al lector con denominar todas las consecuencias que sufrimos todos en un mundo inhumano e injusto, destrozado la maravilla creación de Dios. Vale la pena para culminar este rizoma entreverado de emitir la posición radical que hay que re-civilizar la escalada del mercado y la globalización.

En lo que sigue, se dan las vías de cómo continúa la indagación; que no obedecen a las investigaciones parceladas reduccionistas, donde el método parece el centro, y las subjetividades del investigador pasan a quedar delegadas, prohibidas; aquí las autoras son agente de cambio y se re-civilizan con su formación, su accionar, sus conocimientos y sobre todo la reforma de su con-formación, sin olvidar que nos amemos unos a los otros, como así lo quiere Dios y es su mandamiento.

\section{Rizoma: denominación, transparadigma y transmetodología, transmétodo y de la investigación}

Una característica de las investigaciones tradicionales bajo metodologías modernista es la divisoria capitular en la forma de presentar las indagaciones, en un ir sin venir; cuestión contraria es el rizoma. Así, lo primero que se observa en el comienzo de esta indagación es la denominación de rizoma en la estructura de la investigación; se trata de una anti-genealogía que rompe con las estructuras estáticas divisorias de presentar las indagaciones en las que las partes se dividen indisolublemente en un ir si un venir como se acaba de decir. Acá la organización no responde a ningún modelo estructural o generativo. Deleuze y Guattari (1980) consienten que el rizoma es un sistema "acentrado, no je-rárquico y no significante (...) ri-zoma está hecho de mesetas (...) una región continua de intensidades, que vibra sobre sí misma, y que se desarrolla evitando cualquier orientación hacia un punto culminante o hacia un fin 
exterior" (p.26). El rizoma es una irreverencia al modernismo en el que se dividen las tradicionales investigaciones que comienzan con una introducción y culminan con una conclusión.

Se usa por primera vez la división en rizomas, en vez de capitular, en la Rodríguez (2017), el rompimiento con la tradicionalidad modernista de las indagaciones denotadas en las estructuras tradicionalistas de las investigaciones cualitativas o cuantitativas o las denominadas mixtas. Deleuze y Guattari (1980), han dedicado todo un nombre de rizoma al prólogo de su texto Mil Mesetas. Capitalismo y esquizofrenia. El nombre de rizoma esta compaginado y en perfecta similitud con fractales.

Ratifica el rompimiento con la tradicionalidad de capítulos lo rizomatico, Deleuze y Guattari (1980), afirma que "el rizoma rompe con la estructura vertical de la raíz, mas no por ello se constituye en un sistema "dialéctico", es decir, horizontal (...) Sino que se convierte en una red acéfala y asimétrica. Anarquismo ontológico" (p.23).

Por otro lado, el rizoma como tal no es realizable en las investigaciones modernistas o postmodernistas. Para buscar líneas de salida y que esto sea posible, debemos ubicarnos en la transmodernidad, como civilización que se adopta en paso a la descolonización donde se rescata lo olvidado o soterrado en la modernidad. Dussel (1992), afirma que "la transmodernidad es un nuevo proyecto de liberación de las víctimas de la Modernidad, la "otra-cara" oculta y negada" (p.162). No son pocas las razones sustentadas en Enrique Dussel de como en la transmodernidad se encuentra el asidero necesario para la realización de dicha investigación; sigue afirmando Dussel (1992), "ese proyecto transmoderno será también fruto de un diálogo entre culturas" (p.162).

Se indaga con la investigación transcompleja con transmétodo, que van más allá de los métodos tradicionales, ¿Qué significa transmétodo? afirma Zaá (2017), la transcomplejidad es "transmetódica, concepto que envuelve lo metametódico; constituye y postula un ascenso en el pensamiento (...) se observa un rebasamiento de los tradicionales trasfondos paradigmáticos (...) es un ejercicio de reflexión donde se repiensa permanentemente el statu quo de las ciencias" (p.91). Desde luego dejan estas últimas de erigir como las eruditas del saber para abrirse a lo olvidado y desmitificado.

El transmétodo que analiza la diada ecosofía-antropoética como una re-civilización de la humanidad, como objetivo de la investigación en el proyecto transmoderno y transparadigma transcomplejo es la hermenéutica comprensiva, ecosófíca y diatopica inédita y usada en: Rodríguez (2018a, 2018b, 2018c).

La tarea de dicho hermenéutica no es explicar lo exterior, aquello en lo que la experiencia se expresa, sino comprender la interioridad de la que ha nacido lo relativo a las categorías de las indagaciones; a todos sus saberes; en este caso la hermenéutica comprensiva le permite a la investigador, de acuerdo con Rodríguez (2017), la hermenéutica interpela los territorios temáticos del conocimiento, la imaginación creadora, la actitud transvisionaria, la irreverencia frente a lo conocido, los modos de interrogar la realidad, la criticidad en el hermeneuta (las autoras), la libertad de pensamiento entre otras. Es interpelar la tradicionalidad de la civilización, la ética caducada, la ecología; categorías claves de la indagación.

En cuanto al carácter complejo de la hermenéutica anidada por la ecosofía, Pupo (2017), afirma que "la ecosofía no renuncia ni a la ciencia ni a la tecnología, simplemente subraya que el uso que hacemos de ellas no satisface las necesidades humanas básicas como un trabajo 
con sentido en un ambiente con sentido" (p.10). No ha de olvidarse que justamente la ciencia y tecnología es anidada por los saberes soterrados en la complejidad; no es motivo de dicho transparadigma desmitificar la cientificidad; lo que si asume es que esta no es suficiente.

Pupo (2017), afirma que "la hermenéutica ecosófica, una pragmática existencial cósmica, crítica cuyas interpretaciones siguen una lógica plural con sentido cultural y complejo, pero al mismo tiempo, comprometida con el destino del hombre y la tierra" (p.10). En ese sentido la transmodernidad en plena consideración respalda el carácter ecosófico de las investigaciones transcomplejas.

De la hermenéutica en cuestión como transmétodo, afirma Santos (2002), que su carácter diatópico consiste en "elevar la conciencia de la incompletud a su máximo posible participando en el diálogo, como si se estuviera con un pie en una cultura y el otro en la restante. Aquí yace su carácter diatópico" (p.70). Es así como desde este carácter se respeta la diversidad cultural, por ejemplo, en estudios de cultura y donde quiera que se deban versar saberes científicos y saberes soterrados; tal cual Santos (1998), respalda el hecho de que la hermenéutica diatópica no sólo requiere un "tipo de conocimiento diferente, sino también un proceso diferente de creación de conocimiento. Requiere la creación de un saber colectivo y participativo basado en intercambios cognitivos y emotivos iguales, un conocimiento como emancipación, más que un conocimiento como regulación" (p.30).

Desarrollando el carácter diatópico no va reñido con el ecosófico; por el contrario uno explica y respalda al otro y es de alta importancia en la consideración de la complejidad de las crisis mundiales desplegar una hermenéutica ecosófica, una conciencia ecológica que propicie el acaecimiento y aseveración de una cultura ecosófica, donde el ser humano vea la naturaleza integrada parte de su cuerpo y de su espíritu. Una propuesta que se lleva a cabo en la etnografía crítica como reconocimiento de lo nuestro y promoción de los saberes a ser reconocidos para habitar en el planeta sin destruirlo, su preservación.

En Panikkar (2007), la "hermenéutica diatópica", permite ir no sólo más allá de la distancia temporal, sino también, y esto es lo fundamental, de los lugares comunes teóricos, los tópoi culturales (p. 154).

Desde luego, en general para la realización de la indagación hermenéutica comprensiva, diatópica y ecosófica se pasan por niveles que están profundamente relacionados estos son: los planteados por Santos (2003), analítico, empírico y propositivo. En el caso de Santos (2003) en el primer momento se interpretará y teorizará el devenir de la problemática que se estudia, extrayendo las ideas fuerzas de las obras de los diferentes autores de la investigación y categorías intervinientes; más aun revisando la epistemología de dicha problemática. El segundo momento: el empírico, estará enfocado a interpretar la complejidad de las categorías y el devenir y de la epistemología de esta, en su modo de concebirse, y en especial de cómo se ha llevado a la práctica.

Así mismo, el investigador realizará énfasis en el pensamiento de varios autores confrontando su pensamiento con el de los diferentes autores revisados. El tercer momento se encauzará a la prefiguración del objeto de estudio, para el fortalecimiento de este se desprende de los autores y va a buscar un discurso propio de construcción, donde reconstruye y construye y se analiza civilización y su posibilidad de re-significarse. Los dos primeros momentos se cumplieron hasta el Rizoma que viene y en los dos últimos Rizomas que vienen se cumplieron el momento propositivo de dicho transmétodo. 


\section{Rizoma: la antropoética como el viraje del accionar humano}

El comportamiento inhumano del humano está ante todo regido por una falsa promesa de supremacía de que siendo el hombre el principal y más importante del universo, creencia llevada de la modernidad y del humanismo, la adaptación de la tierra al ser humano ha llevado a que este la mutile, y con esto a sus congéneres. La misión de la antropoética es reflexionar y dar un viraje al accionar humano en tanto regresando la ética alcanzaría su condición de ciudadano.

La ciudadanía, categoría clave en la investigación y la con-formación con la antropoética tiene una íntima relación y se vinculan con la función del sujeto político y el sujeto histórico de una sociedad. Morín (2002), hace reflexionar sobre la condición de ciudadano, del ser humano, explicando que un ciudadano, en la mayoría de los casos, o es lo que se espera, ser solidario, responsable y arraigado a su patria, esto es lo que las autoras denomina la pertenencia a un lugar que le dio abrigo, donde nace y lucha, por esto, la educación debe contribuir a la autoformación de la persona en su condición humana, su vida y su ciudadanía. Se trata de un ser humano con una conciencia compleja más allá de la individualidad, con fines de entender la humanidad, es un ciudadano planetario, esta apuesta de la antropoética se hace en medio de la incertidumbre.

La antropoética viene entonces en esa conformación del ciudadano a significar un ser humano ético que acciona como sujeto, que no puede serlo sino cumple como ciudadano del mundo; es decir un individuo con obligaciones morales para con él, sus semejantes y la naturaleza. Esta con-formación, desde luego, se debe dar desde la educación con ciudadanos que investiguen su propia práctica educativa, sean ciudadanos críticos que se inmiscuyan en los problemas del país y vayan a aportes sustantivos para su solución, la plena conciencia de la excelencia educativa necesaria de estos tiempos. Con ello, la formación de científicos y profesionales; pero también se trata de una antropoética en la ciudad, en el hábitat popular, en donde quiera exista un ser humano. Esta ética del género humano no es elitista de las instituciones educativas; es también la del político que con sus decisiones desangra a la humanidad.

Desde luego, hay que indagar en la incomprensión del ser humano, su comportamiento antiético con la tierra, su casa, de donde surge esta imposibilidad antihumana, según Molano (2012), "la incomprensión también surge de la imposibilidad de ver la complejidad, es decir, reducir el todo a una de sus partes. (...) La reducción de la formación de investigadores educativos al contexto disciplinar es tanto como negar que el ser humano influye sobre el medio y viceversa" (p.9).

La formación del ciudadano como el capital intelectual, se trata de la regeneración moral, de la re-civilización, Morín (2006) afirma "la regeneración moral que necesita la integración, en nuestra propia conciencia y personalidad, de los preceptos de la autoética, a fin de reactivar nuestras potencialidades altruistas y comunitarias" (p.194). Es volverse hacia la formación continua, hacía la humanización, que solo el ser humano puede construir; aportes que respalda Rodríguez (2014).

La antropoética tiene en si un tipo de ecosofía, Colorado (2015), afirma que es una "ecosofía pedagógica compleja y profunda, concebida eticidad compleja y ecología de la acción para la formación humana, mediada por grandes ideas para preparar al hombre para el trabajo 
creador y la vida con sentido, en camino hacia la era planetaria" (p.5). El viraje del ser humano en su accionar es ejemplar desde la ética del género humano que atiende la trinidad: individuosociedad y - especie. El bien pensar como comprender bien, adecuadamente no reduccionista, que lleva con la ecosofía la re-civilización de la humanidad, que en lo que deviene se presenta en el momento propositivo del transmétodo.

\section{Rizoma: ecosofía-antropoética como la re-civilización de la humanidad}

En este rizoma del momento propositivo de la hermenéutica comprensiva, ecosófica y diatópica y con ello el objeto de estudio en su conformación: analizar la diada ecosofíaantropoética como una re-civilización de la humanidad. Para ello desde Edgar Morín y las subjetividades como sujeto re-vindicado con la re-civilización se esgrime lo siguiente.

Desde los nueve mandamientos de la diada: antropolítica - antropoética, en Morín (2006) se dan algunas reivindicaciones de la humanidad, con pensares ecosóficos. Para ello, se complejizan estas categorías, que en conjunción con la creación a la humanidad y el amor de Dios, nuestro creador, en conexión con sus mandamientos bíblicos intentaremos re-vindicarnos con la humanidad en primera instancia.

En cuanto al primer mandamiento, Morín (2006), lo define como "la toma de conciencia de la identidad humana común a través de las diversidades de individualidad, de cultura, de lengua" (p.181). Habla acá de la magnificencia de nuestra creación, de que el ser humano tiene en sí mismo, la sabiduría de Dios, en Sociedades Bíblicas Unidas (1960) (1 Cor. 1:30), somos coherederos con Jesucristo de Nazaret, en el reconocimiento de la sabiduría que emana de Dios y que es el máximo nivel de la Inteligencia Espiritual así podemos re-civilizar la inconciencia, desde la aceptación que somos uno en el planeta. La aceptación de la complejidad de la vida, que es la vida del planeta, que el centro es este y que nos debemos antropoéticamente a una responsabilidad social, pero también espiritual, ecológica, y de la vida en el universo.

Esta toma de conciencia de la identidad humana a través de la diversidad de las culturas, religiones y maneras de ser en la aceptación del otro en nosotros y viceversa, es el reconocer que podemos acercarnos a Dios con libertad y confianza Sociedades Bíblicas Unidas (1960) (Ef. 3:12). Recobrando con ello que parte de la identidad está en la trinidad de Panikkar (1999): Dios-hombre-cosmos, y que somos la luz Sociedades Bíblicas Unidas (1960) (Ef. 5:8). Es el reconocimiento del individuo-sociedad y especie en esa trinidad donde ninguna de la dos (las triadas) se desunen.

La grandeza de la creación mostrada por Dios a través de las diversidades de individualidad, de cultura, de lengua, de naturaleza muestra como nuestro gozo se desborda Sociedades Bíblicas Unidas (1960) (Flp. 1:26), de admiración y así debemos salvaguardarnos, cuidarnos al igual que la naturaleza, los congéneres, toda vida que en igual grado de importancia se aceptan y aman; el amor en pleno esplendor.

Aquí deviene la urgencia de re-significar y re-civilizar la condición humana, Osorio (2011), avalado por Morín (2011), afirma que concebir la Humana Conditio como una emergencia planetaria demanda de una nueva forma de pensar, requiere de un pensamiento complejo idóneo de pensar metamorfosis, ético y política de la humanidad en la era planetaria. La antropolítica así es la condición cómo conseguimos pensar complejamente lo urgente de la crisis de la humanidad, que se ha vuelto planetaria. La antropolítica tiene que ver con una nueva condición de recapacitar la humanidad en la era planetaria. 
En el segundo mandamiento, Morín (2006), lo define como: "la toma de conciencia de la comunidad de destino que en adelante une cada destino humano al del planeta, incluida la vida cotidiana" (p.181). Este mandamiento está unido al primero: vivimos en la misma casa, y con un destino común; ejerciendo el hecho de que somos santos y fieles Sociedades Bíblicas Unidas (1960) (Col. 1:2), entonces desde esa magnificencia de la condición humana nos desterramos del odio, el rechazo, el racismo, el desamor y nos cobijamos bajo el manto de bondad otorgado por Dios para cuidarnos de la inhumanidad del ser humano.

Para ello, se requiere: paz, basta de guerras y destrozos de nuestros congéneres, la violación a nuestras condiciones de vida, Panikkar (2006), afirma que "la paz requiere algo más que buena voluntad; requiere también comprensión del otro, lo cual no es posible sin transcender el propio punto de vista, sin interculturalidad" (p.11). Se trata de una conducta antropoética, un pacto de cero agresiones, tenemos nuestra esperanza de gloria Sociedades Bíblicas Unidas (1960) (Col.1:27) y hacia allí debemos ir.

En esta toma de conciencia de la comunidad destino, es menester acudir a re-significar que es la tierra, no es un sujeto, que responde que se comunica, está vivo tiene sus expectativas y nos pide que nos adaptemos a ella, re-civilizar las concepciones del conocimiento reduccionista de los que es la tierra, es emergen e hacerlo desde un conocimiento ecosófico, partiendo que, de acuerdo con Panikkar (2005) "la ecosofía va mucho más allá de la visión de la Tierra como un ser vivo; ella nos revela la materia como un factor de lo real tan esencial como la consciencia o lo que solemos llamar divino" (p.202).

Con la lucidez del ser humano nos convertimos en plena madurez Sociedades Bíblicas Unidas (1960) (Col. 1:28), en la medida que aceptamos que dependemos de todos los demás del planeta, que estamos regulados en una conducta que nos da muerte segura o vida eterna en una tierra reinventada por Dios. En Él están escondidos todos los tesoros de sabiduría y conocimiento para nosotros Sociedades Bíblicas Unidas (1960) (Col. 2:3).

En el tercer mandamiento, Morín (2006), lo define como: "la toma de conciencia de que las relaciones entre humanos están devastadas por la incomprensión, y que debemos educarnos en la comprensión no solo hacia los allegados, sino también hacia los extranjeros y lejanos en nuestro planeta" (p.181). El ser humano en su humanidad, incomprensión, falta de amor ha llegado a atacarse a sí mismo. Sin embargo, Jesucristo era un hombre completamente diferente. De hecho, sus enemigos lo criticaban diciendo: Sociedades Bíblicas Unidas (1960) "este hombre recibe con gusto a pecadores, y come con ellos" (LC. 15:2). Jesús era amable, paciente y tolerante; no juzgaba a la gente sino que quería ayudarla a conocer a Dios. Todo lo que hacía, lo hacía porque amaba a las personas Sociedades Bíblicas Unidas (1960) (Jn. 3:17; 13:34).

Si somos coherederos con Jesucristo, de hecho así somos por mandato de Dios y herederos del Reino debemos acudir al amor, y en este sentido Panikkar (2006), afirma que "no hay amor sin comprensión, ni comprensión sin conocimiento mutuo. (...). Estamos de nuevo en el círculo vital: sin el reconocimiento de la realidad como «gracia» nada tiene sentido. Sentir su necesidad ya es un conocimiento" (p.121).

Es clave entonces, desde la sabiduría conocernos, reconocernos en el diferente, resguardarnos en y con humildad de nuestros propios demonios de incomprensión, re-civilizar la incomprensión, re-civilizar el desamor, re-civilizar la intolerancia, re-civilizar el egoísmo. El amor es la clave para ser más tolerantes, pues abre nuestra mente y corazón para aceptar a los 
demás a pesar de sus imperfecciones y diferencias. Sociedades Bíblicas Unidas (1960), "continúen soportándose unos a otros y perdonándose liberalmente unos a otros si alguno tiene causa de queja contra otro" (Col. 3:13). Pero también, el trato justo de la tierra y los recursos, con la toma de conciencia ecosófica, con ello Panikkar (1994), nos dilucida "la ecosofía es una voz profética contra la intención pragmática de la ecología que busca una explotación "racional" de las riquezas naturales bajo el concepto de explotación blanda" (p.114).

La clave en el amor: el dialogo, la diatopía, la aceptación de los topoi, en tanto de acuerdo con Panikkar (2003), el diálogo es el modo de superar el solipsismo y el egoísmo de todo tipo. Nosotros nos realizamos a nosotros mismos en la medida en que participamos activamente en el destino de que todo el cosmos. Desde luego, la clave acá es ejercer un verdadero servicio al otro, es según Osorio (2011), "una política de los poderes para sacrificar a los que no son de su grupo político, sino que una antropolítica para la salvar a la humanidad realizándola" (p.156).

En el cuarto mandamiento, Morín (2006), lo define como la toma: "de conciencia de la finitud humana en el cosmos, que nos conduce a concebir que, por primera vez en su historia, la humanidad debe definir los límites de su expansión material y correlativamente emprender su desarrollo psíquico, moral, mental" (p.181). Si tal vez la conciencia de que tenemos finitud en este cuerpo fuera un recordatorio de que hacer con nuestro tiempo, y que hacer para ganarnos la resurrección de acuerdo con la doctrina de Dios el mundo sería más humano, y tendríamos más compasión por el otro. Sociedades Bíblicas Unidas (1960), "Y de la manera que está establecido para los hombres que mueran una sola vez, y después de esto el juicio" (He. 9:27).

Para los salvos, la muerte nos lleva a la presencia de Jesucristo: Sociedades Bíblicas Unidas (1960), "estar ausentes del cuerpo, y presentes al Señor" (2 Cor. 5: 8, Flp. 1:23). Tan real es la promesa de la resurrección de los creyentes que la muerte física de un cristiano es llamada "dormir" Sociedades Bíblicas Unidas (1960) (1 Cor. 15: 51, Te. 5:10). Esperamos ese momento cuando Sociedades Bíblicas Unidas (1960), "no habrá muerte" (Ap. 21:4). Es la promesa que ya en la resurrección con un mundo perfecto tendremos vida eterna, luego de la muerte de este cuerpo, de esa conciencia de finitud debemos estar llenos.

Hay que re-civilizar entonces nuestro comportamiento ante el otro, ante el egoísmo, Panikkar (2006), testifica dos intuiciones empíricas germinan en la "conciencia humana de nuestro tiempo: la guerra se convierte en sinónimo de destrucción; victoria no significa vencer una batalla y ninguna victoria aparece como un camino hacia la paz, sino, en todo caso, como un incentivo para la revancha" (p.112).

En el quinto mandamiento, Morín (2006), lo define como: "la toma de conciencia ecológica de nuestra condición terrenal, que comprende nuestra relación vital con la biosfera. La Tierra no es la adición de un planeta físico, de una biosfera y de una humanidad" (p.181). Por ello, la ecosofía como el arte de habitar en el planeta sobrepasa al fracaso de los movimientos ecológicos, el ser humano debe tomar conciencia: Sociedades Bíblicas Unidas (1960), "del Señor es la tierra y todo lo que hay en ella; el mundo y los que en él habitan. Porque Él la fundó sobre los mares, y la asentó sobre los ríos" (SI. 24:1-2).

La tierra clama, y nos preguntamos: ¿aún podemos prolongar la vida en el planeta? Lo que si sabemos que estamos en el deber antropoético de emprender una camino que nos dignifique ante el mundo y Dios Creador y Señor Sociedades Bíblicas Unidas (1960), "ahora pues, si en verdad escucháis mi voz y guardáis mi pacto, seréis mi especial tesoro entre todos 
los pueblos, porque mía es toda la tierra; y vosotros seréis para mí un reino de sacerdotes y una nación santa" (Ex. 19:5-6).

Habla Panikkar (1994), que la ecosofía es una sabiduría-espiritualidad de la tierra misma que se manifiesta al hombre cuando sabe escucharla con amor, más allá de una simple ecología. Hay que superar una cierta actitud ecológica habitual para profundizar mucho más en la investigación de un nuevo equilibrio entre materia y espíritu. Es menester escuchar el clamor, porque la tierra a la cual entras para poseerla, no es como la tierra de Egipto de donde vinisteis, donde sembrabas tu semilla, y la regabas con el pie como una huerta de hortalizas, sino que la tierra a la cual entráis para poseerla, tierra de montes y valles, bebe el agua de las lluvias del cielo Sociedades Bíblicas Unidas (1960) (Dt. 11:10-15). Es una tierra que el Señor tu Dios cuida; los ojos del Señor tu Dios están siempre sobre ella, desde el principio hasta el fin del año.

Desde luego acá, pensamos con Osorio (2011), cuando afirma que es menester una antropolítica, que siendo una política que comprenda la gran complejidad humana en su proceso de planetarización, es re-civilizar el pensamiento, el accionar como una forma de pensar la humanidad como comunidad de destino planetario para salvar la humanidad realizándola, y no hundiéndose todos con ello, es la oportunidad del ser humano de reivindicándose.

En el sexto mandamiento, Morín (2006), lo define como: "la toma de conciencia de la necesidad vital del doble pilotaje del planeta: la combinación del pilotaje consciente y reflexiva de la humanidad con el pilotaje ecoorganizador inconsciente de la naturaleza" (p.181). Se trata de tener un pie en lo reflexivo uno en lo ecoorganizador que manteniendo el balance de Sociedades Bíblicas Unidas (1960), "Ios que somos fuertes (...) debemos soportar las debilidades de los que no son fuertes, y no estar agradándonos a nosotros mismos. Porque hasta el Cristo no se agradó a sí mismo" (Ro. 15:1,3).

Con ello se re-civilizaría la posesión desmedida por el disfrute y salvaguarda del otro soterrado, Panikkar (1994), afirma que la función de la especie humana no es la de dominar la tierra, sino que lo que tiene que hacer es cultivarla, empezando por el cultivo personal de uno mismo, siguiendo por el cultivo del alma y continuando con él la tierra. Cuerpo, alma y tierra son tres aspectos de una misma cultura y realidad.

Pese a la aceptación de la diversidad en todo sentido, en las culturas por ejemplo es urgente también la pertinencia al lugar donde se habita protegiendo al foráneo; Morín (2011), "crear una nueva forma de pensamiento que permita conocer cuál es nuestra realidad nacional desde nuestra propia óptica y no vista por actores externos a nuestros países" (p.142). Nos habla de lo local, lo cultural propio de nuestra región, en el abrazo de los topoi, de la diversidad, de lo diferente. Perfeccionarse desde el otro, conocerse reconociéndose en el otro, pero también en la naturaleza; en la grandeza y majestad de lo que tenemos, sentirse propio de ello es proteger; ese sentido que el resto después de nosotros clama comunicarse con y esa retroalimentación nos reclama sentido de responsabilidad, la autoética también como la antropoética.

En el séptimo mandamiento, Morín (2006), lo define como: "la toma de conciencia cívica planetaria, es decir de la responsabilidad y la solidaridad hacia los hijos de la tierra" (p.181). Se trata del bien común puesto en escena, la re-civilización del egoísmo, Sociedades Bíblicas Unidas (1960), "mi conciencia da testimonio conmigo en [conformidad con el] Espíritu Santo" (Ro. 9:1).

La conciencia planetaria debe llevar a comunicarse con el ambiente, los animales, los congéneres, para ello comprender es amar y amar necesita respeto y comprensión. Panikkar 
(2003), afirma "querer comprender al otro supone solo la mitad de la plataforma para un diálogo auténtico. Yo mismo debo estar dispuesto a ser comprendido por el otro, y también preparado para posibles incomprensiones. Y lo mismo vale para la otra parte" (p.51).

Comprender en el bien pensar ante de juzgar y no aportar es llegar a la máxima de que no olvidemos que Jesús dijo: Sociedades Bíblicas Unidas (1960), "Dejen de juzgar, para que no sean juzgados" (Mt. 7:1). De críticas están llenos escenarios enteros, pero seres humanos trabajando bajo el convencimiento de la re-civilización son escasos, pero hay un camino y está allí busquemos la mejor ruta de amor hacia el planeta entero. Sociedades Bíblicas Unidas (1960) "él justo se preocupa de la vida de su ganado, pero las entrañas de los impíos son crueles" (Pr. 12:10).

En el octavo mandamiento, Morín (2006), lo define como: "la prolongación en el futuro de la ética de la responsabilidad y la solidaridad con nuestros descendientes, de ahí la necesidad de una consciencia con un objetivo dirigido alto y lejos en el espacio y el tiempo" (p.181). Es un mandamiento complejizado con todos los demás, es la máxima aspiración antropoética, no se olviden de la solidaridad y de hacer el bien, que tales sacrificios son los que agradan a Dios, Sociedades Bíblicas Unidas (1960) (Heb. 13:16).

La conciencia con Panikkar (2003), de que "la Tierra no es un simple objeto, es también un sujeto, un Tú para nosotros, con quien debemos aprender a dialogar. Así podremos descubrir que la ecosofía tiene un cierto papel revelador" ( $p .33$ ). Se trata de la maravilla cristiana, mandato de Dios: sobrellevad los unos las cargas, y así cumplirán la Ley de Cristo, Sociedades Bíblicas Unidas (1960) (Ga. 6:2). De la misma manera, deja que tu luz brille ante los hombres, para que vean vuestras buenas obras y glorifiquen a vuestro Padre que está en los cielos (Mateo 5:16).

En el noveno, y último mandamiento, Morín (2006), lo define como: "la toma de conciencia de la Tierra-Patria como comunidad de destino/origen/perdición. La idea de TierraPatria no niega las solidaridades nacionales o étnicas, y de ningún modo tiende a desenraizar a cada cual de su cultura" (p.181). Hay que navegar en ese lago de incertidumbre de la que Edgar Morín incluye los topois, los polos opuestos en apariencia, que van en el mismo destino común, las parcelas de salvación en una tierra que muerte no existen. Re-civilizar el desamor, "y las multitudes le preguntó: "entonces, ¿qué debemos hacer?" Y él les respondió: Sociedades Bíblicas Unidas (1960) "él que tenga dos túnicas, es compartir con el que no tiene, y el que tiene comida debe hacer lo mismo" (LC. 3:10-11).

La conciencia de la Tierra-Patria como comunidad de destino, según Panikkar (2006), de "una cierta trinidad es una constante humana: en casi todas las tradiciones de la humanidad parece que se ha descubierto que la realidad es triuna (...) son precisamente lo que nosotros llamemos aquí Dios, Hombre y Cosmos" (p.106). Por ello, el amor a nuestros semejantes, y a Dios como el amor más grande es deseable en la re-civilización, Sociedades Bíblicas Unidas (1960), "este es mi mandamiento: que os améis los unos a los otros como yo os he amado" (Jn. 15:12).

Es importante retomar el cambio de pensamiento, re-formarlo, re-construirlo, volver a significar el planeta en la vida del ser humano, re-civilizar el pensamiento, es que se proponga, de acuerdo con Morín (2011), "mejorar las relaciones entre los humanos (pueblos, grupos e individuos) debe más que cualquier cosa, basarse únicamente en una concepción del mundo, del hombre, de la sociedad y de la historia, pero también en una concepción de la era planetaria" (p. 44) 
En lo que sigue la parte final de la indagación, la del momento propositivo.

\section{Rizoma: A modo de conclusiones en el camino de la civilización}

Es importante clarificar que en este cierre de la investigación transmétodica donde se analizó la diada ecosofía-antropoética como una re-civilización de la humanidad; bajo el erige de la hermenéutica comprensiva, ecosófica y diatópica, se dan elementos que deben estar presentes al culminar las indagaciones donde se use dicho transmétodo.

En primer lugar, sólo es posible su cabal uso fuera de los paradigmas, bajo el transparadigma transcomplejo y en un espacio transmodernista; de donde sin ataduras y en el rescate de lo olvidado lo diatópico y ecosófico; son estas categorías investigativas con la antropoética y antropolítica quienes desde el cristianismo se re-civiliza la humanidad en la presente indagación. Para ello la conciencia debe re-civilizarse a una plenitud del hombre, Panikkar (1998), habla de una cristofanía que es la manifestación de Jesucristo a la consciencia humana; una experiencia real con nuestro salvador. No se trata de religiones instauradas en el poder de la humanidad en una especie de autoritarismo. Se trata de acuerdo con el autor nombrado que Cristo es la plenitud de la vida, esta plenitud, que pertenece al kairos cristiano del tercer milenio. Es una búsqueda de las preguntas iniciales: ¿quiénes somos?, ¿cuál es nuestra misión?, es la etapa menos agresiva y contemplación de nuestra misión en la tierra. Un accionar de amor con todo y todos.

En segundo lugar, todo cierre en dichas indagaciones son aperturas, por ello la recivilización es un tema que ya ha sido aperturado en pensamientos complejos y que puede irse auto re-civilizando en cada uno desde el bien pensar, la comprensión correcta y el accionar adecuado.

En tercer lugar, las investigadoras en su carácter transcomplejo salen de las ataduras autoritarias de los investigadores para ejercer el poder de un conocimiento inacabado en cualquier indagación, donde esté presente dicho transmétodo. Por ello, es claro que las indagaciones son auto aperturas subjetivas que el investigador por ser doliente y agente de cambio, promotor de la re-civilización que todos los días intenta un cambio de pensamiento de su formación tradicional, de su pensar tradicional a un pensamiento unitivo, ecosófico, antropoético y en la búsqueda de la bondad y las mejores excelsitudes de su propia condición humana.

En cuarto lugar, la transmodernidad en especial, como proyecto de realización de dicho transmétodo va fuera de epistemes de la modernidad, los reconstruye y va a un transespisteme nunca definitivo; más allá de los conocimientos tradicionales. Es de estar consciente y es bien pensar que si el proyecto de la modernidad, la globalización y tantos proyectos hegemónicos que castran las subjetividades y verdadero sentir y finalidad del hombre en la tierra, es imposible realizar allí este tipo de plenitudes, por ello la transmodernidad es un espacio de excelencia junto a la transcomplejidad como transparadigma para re-civilizar a la humanidad.

Finalmente en quinto lugar, la línea de investigación donde se ubica la indagación de las autoras se titula: Transepistemologías de los saberes y transmetodologias transcomplejas. Y como se ha hablado de mandamientos y el amor es la excelsitud más importante a mostrar en la humanidad, al re-vindicar nos despedimos con el devenir del Primer y Segundo Mandamiento de DIOS, cuando en Sociedades Bíblicas Unidas (1960) Mat. 22:34-39, un intérprete de la Ley 
le pregunto Maestro: ¿Cuál es el principal mandamiento de la Ley? Él le respondió: Amarás al Señor tu Dios con todo tu corazón y con toda tu alma y con toda tu mente. El Segundo Mandamiento es semejante a éste: Amarás a tu prójimo como a ti mismo.

\section{Referencias bibliográficas}

Colorado, Jorge. (2015). La antropoética en el Pensamiento Complejo de Edgar Morín y su concreción en la educación universitaria. Trabajo de Grado. Doctor en Pensamiento Complejo. Multidiversidad Mundo Real Edgar Morín. Una visión integradora. México.

Deleuze, Gilles y Guattari, Félix. (1980). Rizoma (Mil Mesetas 1980). Minuit. París.

Dussel, Enrique. (1992). La ética de la liberación: ante el desafío de Opel, Taylor y Vatio con respuesta crítica inédita de K.-O. Opel. Universidad Autónoma del Estado de México. México.

Encinas, María. (2009). Estudio antropológico del comportamiento ante la muerte: Humanidad e inhumanidad. Cauriensia. Volumen IV. España. (Pp. 293-328).

Lorenz, Konrad. (1984). Los ocho pecados mortales de la humanidad civilizada. Plaza \& Janes Editores. S. A. España.

Molano, Alba. (2012). La complejidad de la educación ambiental: una mirada desde los siete saberes necesarios para la educación del futuro de Morín. Revista de Didáctica Ambiental. Volumen11. España. (Pp.1-9).

Morín, Edgar y Kern, Anne. (1993). Tierra Patria. Editorial Nueva Visión. Argentina.

Morín, Edgar. (1999). Los siete saberes necesarios para la educación del futuro. UNESCO.

\section{Francia.}

Morín, Edgar. (2002). Ética y globalización. Los desafíos éticos del desarrollo. S.E.: España. Morín, Edgar. (2006). El Método VI. La ética. Ediciones Cátedra. España.

Morín, Edgar. (2008). Estamos en un Titanic. Ediciones Cátedra. España.

Morín, Edgar. (2011). La Vía: Para el Futuro de la Humanidad. Editorial Paidós. Francia.

Osorio, Sergio. (2011). La metamorfosis de la humanidad en la era planetaria y la emergencia de la antropolítica. Revista de Relaciones Internacionales, Estrategia y Seguridad. Volumen 6. Número 2. Colombia. (Pp.139-161).

Panikkar, Raimón. (1994). Ecosofía: Para una espiritualidad de la Tierra. San Pablo. España. Panikkar, Raimón. (1998). La plenitud del hombre una Cristofanía. Ediciones Siruela. España. Panikkar, Raimón. (1999). La intuición cosmoteándrica: las tres dimensiones de la realidad. Trotta. España.

Panikkar, Raimón. (2003). El diálogo indispensable. Paz entre las religiones. Ediciones Península Barcelona. España.

Panikkar, Raimón. (2005). De la mística. Experiencia plena de vida. Herder. España.

Panikkar, Raimón. (2006). Paz e interculturalidad. Una reflexión filosófica. Herder. España.

Panikkar, Raimón. (2007). Mito, fe y hermenéutica. Herder. España.

Pupo, Rigoberto. (2017). La cultura y su aprehensión ecosófica. Una visión ecosófica de la cultura. Editorial Académica Española. Alemania.

Rodríguez, Milagros. (2014). De la educación a la teoría del capital humano: insuficiencias y críticas. Praxis Investigativa ReDIE. Volumen 6. Número 10. México. (Pp. 57-66). 
Rodríguez, Milagros. (2017). Fundamentos epistemológicos de la relación patrimonio cultural, identidad y ciudadanía: hacia una educación patrimonial transcompleja en la ciudad. Tesis de Grado. Doctora en Patrimonio Cultural. Universidad Latinoamericana y el Caribe. Venezuela.

Rodríguez, Milagros. (2018a). La educación patrimonial descolonizada: un espacio por construir en la transmodernidad. Praxis Educativa ReDIE. Volumen 18. México. (Pp. 8-32).

Rodríguez, Milagros. (2018b). La Educación Patrimonial y la Formación Docente desde la Transcomplejidad. TELOS Revista de Estudios Interdisciplinarios en Ciencias Sociales. Volumen 20. Número 3. Venezuela (Pp. 431-449).

Rodríguez, Milagros. (2018c). El patrimonio cultural en la transmodernidad como símbolo de la identidad: visiones transcomplejizadas. Revista Digital de Gestión Cultural. Volumen 13. México. (Pp. 1-26).

Santos, Boaventura. (1998). Por una concepción multicultural de los derechos humanos. Universidad nacional Autónoma de México. México.

Santos, Boaventura. (2002). Hacia una concepción multicultural de los derechos humanos. EL OTRO DERECHO. Volumen 28. Colombia. (Pp. 59-83).

Santos, Boaventura. (2003). Crítica de la Razón Indolente Contra el Desperdicio de la

Experiencia. Volumen I. Para un Nuevo Sentido Común: La Ciencia, El Derecho y La Política En La Transición Paradigmática. Editorial Desclée De Brouwer, S.A. España. Sociedades Bíblicas Unidas. (1960). Santa Biblia. Versión Reina-Valera. Venezuela.

Zaá, José. (2017). Pensamiento filosófico transcomplejo. Escriba Escuela de Escritores. Venezuela. 